Orbis Tertius, vol. XXVI, $n^{\circ}$ 33, e191, mayo-octubre 2021. ISSN 1851-7811

Universidad Nacional de La Plata

Facultad de Humanidades y Ciencias de la Educación

Centro de Estudios de Teoría y Crítica Literaria

\title{
Salón de belleza de Mario Bellatin: la preparación de la novela
}

\section{Mario Bellatin's Salón de belleza: the preparation of the novel}

Juan Pablo Cuartas

jpablocuartas@gmail.com

Universidad Nacional de La Plata, Argentina

Recepción: 07 Junio 2020

Aprobación: 11 Diciembre 2020

Publicación: 03 Mayo 2021

Cita sugerida: Cuartas, J. P. (2021). Salón de belleza de Mario Bellatin: la preparación de la novela. Orbis Tertius, 26(33), e191. https://doi.org/10.24215/18517811e191

\begin{abstract}
Resumen: Publicada en 1994, la novela Salón de belleza sigue siendo discutida, en parte por una temática siempre actual para los seres humanos como son las pandemias a nivel global, pero especialmente porque el autor, Mario Bellatin, retorna a la obra con operaciones que siguen la estela que la misma ha ido dejando en relecturas, interpretaciones y hasta réplicas teatrales. Lo ya escrito es condición de posibilidad de la escritura y, simultáneamente, la nueva escritura es transformación de lo ya escrito. El presente trabajo indaga este doble movimiento repitiendo esa intervención: de las modificaciones presentes en las últimas ediciones de Salón de belleza se va hacia los primeros manuscritos para releerlos y transformar su sentido.
\end{abstract}

Palabras clave: Literatura latinoamericana, Enfermedad, Lectura, Manuscrito, Bellatin.

\begin{abstract}
Published in 1994, the novel Salón de belleza is still debated, partly due to its global pandemics theme, always topical to human affairs, but especially because the author, Mario Bellatin, returns to his work with operations that follow its trail along re-readings, performances and even theatrical versions. What is already written is a condition for the possibility of writing and, simultaneously, new writing is a transformation of what is already written. The present work explores this double movement by repeating this intervention: starting from modifications present in the last editions of Salón de belleza, towards the first manuscripts, in order to re-read them and transform their meaning.
\end{abstract}

Keywords: Latin-American Literature, Disease, Reading, Manuscript, Bellatin.

La única satisfacción verdadera que un escrito publicado puede darme es cuando, por algunas cartas de lectores desconocidos, puedo convencerme de que el escrito ha respondido a una demanda que se ignoraba = definición de libro vivo

Barthes, La preparación de la novela, 2005, p. 210

\section{1-INTRODUCCIÓN}

Salón de belleza, cuarta novela publicada de Mario Bellatin, ha sido incluida recientemente en antologías sobre enfermedades, pestes y pandemias ${ }^{1}$, especialmente en razón de los estragos internacionales ocasionados por el Covid 19. Cabe recordar que en un comienzo la novela tuvo como horizonte otra pandemia (el VIH $)^{2}$ 
y que completaba la trilogía bíblica de la peste, la guerra y demonio: Canon perpetuo (1993) es la guerra del individualismo y un sistema; el demonio y la carne es Efecto invernadero (1992) y la peste corresponde a Salón de belleza (1994) (Bellatin 2014, sp.). Con lo cual tenemos un marco bíblico que estrecha fuertemente los lazos entre las obras. ${ }^{3}$ Sin embargo, las recientes pandemias a nivel global privilegian uno de los términos de la trilogía: Salón de belleza se dispara y no sólo por una recepción lectora y crítica más atenta, sino por el propio autor, que retorna a la obra publicada mas no terminada, como si la corroboración pandémica le diera la razón para volver a esa cantera que sigue irradiando nuevas posibilidades escriturales. Escritura con una autonomía sin determinaciones de otra índole que ella misma, pero una autonomía que se correlaciona con la aparición de nuevos contextos materiales. Ésa es la paradoja que hay que pensar. Porque el escritor no renuncia a su libertad inventiva entregándose a retóricas sociales ${ }^{4}$, pero puede notarse que tampoco busca una escritura lúdica o "experimental”, como se señala desde algunas lecturas críticas. Se sabe, la literatura de Bellatin está plagada de elementos conmutables a fuerza de ser retomados por el escritor para seguir escribiendo; sean hechos construidos o autobiográficos, acaban siendo explicados en términos de piezas de un juego de ajedrez (Martinetto 2016)5 o de "cajas chinas" (Palaversich, 2003, p. 32), ${ }^{6}$ limitando cualquier tipo de intelección que vaya más allá de lo escrito, porque en última instancia, "lo único que es considerado "real” es el discurso, el lenguaje que, además, es también indeterminado" (Martínez Caballero, 2011, p. 13). La cuestión que se plantea al leer estas consideraciones críticas es la siguiente: la constante mutación y repetición de elementos nos deja una decepcionante variación cuyo juego ya hemos visto y que podemos adivinar en cada nueva lectura. Un callejón hermenéutico sin salida que incluso ha despertado explicaciones religiosas o sustancialistas (Nuyts 2019). Este circular desgastante suele cortarse por medio de un esquema representativo que toma los nombres "Moridero" y "enfermo" como mediaciones estéticas o retoricas de un referente problemático (SIDA). Es el camino de la lectura en clave biopolítica. El nuestro será uno que responda a la siguiente pregunta: ¿cómo funciona una escritura incondicional, tendiente a lo intransitivo, que tiene su productividad en contextos concretos y materiales (como una nueva pandemia, pero también el feed-back, las lecturas que despierta, o lo producido por otros artistas, como las puestas en escena de terceros)? Desplegar esta pregunta, creemos, aportará inteligibilidad a la racionalidad del proyecto bellatiniano.

\section{2-SALÓN DE BELLEZA, LA LLEGADA DEL MAL}

Salón de belleza aparece publicada por primera vez en 1994, en la edición de Jaime Campodónico (Lima). Tendrá nuevas ediciones en 1995, en 1997, en 1999 y en sendas recopilaciones de sus relatos tituladas Obra reunida de 2005 y 2013. Todas son reediciones de la novela, sin mayores cambios significativos. La novela vuelve como una especie de ritornello en la producción de Bellatin, al menos en el espacio de lo publicado por el autor ya que se realizaron representaciones teatrales de la obra. Retorna, por ejemplo, en Lecciones para una liebre muerta (2005), obra compuesta por fragmentos pertenecientes a diversos relatos, algunos ya publicados como es el caso de Poeta ciego y Salón de belleza. También deben contarse sus incursiones en el cine, en lo audiovisual al menos: en sus sesiones de "Cine vivo", Bellatin ha llevado a cabo lecturas en vivo mientras proyecta escenas filmadas en su zona residencial. Aquí nos enfocaremos en cierta inflexión percibida por el autor con respecto a la recepción de Salón de belleza. En una entrevista ya citada, el escritor afirma:

Yo vi que gané la batalla frente a ese libro cuando surgió la epidemia de la gripe aviar, porque hay una semejanza: una cuenta pendiente que tiene la humanidad, porque de acuerdo con la gripe española de 1919, que arrasó con el mundo, hubo treinta millones de muertes en una época en que ni siquiera había comunicaciones como las que hay actualmente, que apareció y desapareció. [...] Y la batalla ganada fue que en un diario de México, cuando pusieron libros de peste incluyeron también Salón de belleza. Entonces lograron sacarlo del contexto en donde había sido escrito. La idea ilustra de una manera más clara que puede funcionar un libro, un texto determinado, a partir del entorno, pero también puede funcionar de otras maneras. (Bellatin, 2014, s.p.). 
En el año 2006, antes de que la gripe aviar avanzase sobre América Latina, el escritor ya había señalado su voluntad de separar Salón de belleza de su anécdota inicial. En una entrevista de aquel año, introduce una nota más matizada con respecto a lo que esperaba con la recepción de la novela: ya suponía que la fisonomía del HIV iba a cambiar, lo cual nos hace sospechar que el distanciamiento retórico que tiene Salón de belleza provendría de un cálculo (Bellatin 2006a). ${ }^{7}$ Sin embargo, en la misma entrevista, cuando se le pregunta por la existencia de un Moridero real, en Villa el Salvador, en Lima, afirma: "De alguna manera era como la constatación de que el texto estaba haciendo uso de una suerte de imaginario colectivo. En distintas ciudades del mundo se produjo un efecto similar. Se sabía en cada una de esas urbes de la presencia de un lugar semejante". ${ }^{8}$ Esta nota es la que nos interesa: el cálculo existe, como en todos los escritores, pero este surgimiento producido por la obra, por una escritura distanciada de lo real y sus reflejos, será esa "batalla ganada" que el escritor celebrará años más tarde, luego de los efectos de la gripe aviar, y a la cual le será fiel y que no dejará que quede en la constatación.

Esta "batalla ganada", la liberación de la novela, no terminó sólo en esta constatación. ${ }^{9}$ La edición de Salón de belleza de 2015, a cargo de la editorial Malisia, presenta variaciones significativas en relación a las ediciones anteriores. Primero hay una separación de aquello que mantenían fusionado las glosas anteriores de la novela (Lecciones para una liebre muerta (2005), Disecado (2011): por un lado, el texto de la novela de 1994 y por otro lado, el relato del filósofo travesti en un texto titulado "Kawabata, la escritora, el filósofo travesti y el pez". Además, hay ilustraciones de Zsu Szkurka, quien también trabajará con Bellatin en Elperro de Fogwill de 2015 y Jacobo reload un año antes. En cuanto a las reescrituras se relacionan con los nexos de los episodios relatados: los grandes fragmentos en que se divide el relato están encabezados por frases, adverbios o conjunciones que no estaban en el texto canónico. Las modificaciones que nos interesan aquí tienen que ver con la "enfermedad" tal cual aparece en el relato y tal cual, como veremos, fue leída por la crítica.

En cursiva destaco el texto que será eliminado de una edición a la otra. Así, en la versión de 2009, cuando el narrador relata su visita a los Baños, leemos:

El agua espesa, alterada por las burbujas de los motores de oxígeno y por las selvas que se creaban entre las plantas acuáticas, se parecía al sótano de estos Baños. También vivía el extraño sentimiento producido por la persecución de esos peces grandes que buscaban comerse a los chicos. En esos momentos la capacidad de defensa, lo rígidas que pueden ser las paredes transparentes de los acuarios, eran una realidad que se abría en toda su plenitud. Pero aquellos son tiempos idos que nunca volverán. Actualmente mi cuerpo esquelético, invadido por llagas y ampollas, me impide seguir frecuentando ese lugar (2009, p. 19-20).

Mientras que en la de 2015, se lee:

Revivía el agua espesa, alterada por las burbujas de los motores de oxígeno, así como las selvas que se creaban entre las plantas acuáticas. Experimentaba también el extraño sentimiento producido por la persecución de esos peces grandes cuando buscan comerse a los más pequeños. En esos momentos la capacidad de defensa, lo rígido de las transparentes paredes de los acuarios, se convertían en una realidad que se abría en toda su plenitud. Pero ahora aquellos son tiempos idos que nunca volverán. Actualmente mi cuerpo esquelético me impide seguir frecuentando ese lugar (2015, p. 12).

Las "llagas" y "ampollas", lo más visible de la enfermedad, no aparecen en la versión de 2015. El escritor busca darle menos peso a los elementos que dirigen la lectura de Salón de belleza a relacionarla con el SIDA.

Otro ejemplo, relacionado con el único moribundo con el cual el narrador traba relación:

Tampoco se vaya a creer que yo era un suicida y me entregué totalmente a ese muchacho. Antes de hacerlo tomé mis precauciones y no creo que haya sido precisamente él quien me transmitió los gérmenes. Pero como ya señalé antes, mis gustos cambian con frecuencia y de un momento a otro dejó de interesarme por completo. Retiré la pecera del lado de su cama y lo traté con la distancia que me impongo para todos los huéspedes. Casi al instante el mal atacó todo su cuerpo y no tardó mucho en morir (Bellatin, 2009, p. 27).

Mientras que en la edición de 2015: 
Tampoco vayan a creer que yo era un suicida y me entregué totalmente. Antes de hacerlo tomé mis precauciones. Pero, como dije antes, mis gustos cambian con frecuencia. De un momento a otro dejó de interesarme por completo. Por esa razón, en determinado momento retiré la pecera del lado de su cama y lo traté con la distancia que me impongo para todos los huéspedes. Casi al instante el mal lo atacó con violencia. No tardó en morir (2015, p. 16).

Como vemos, los "gérmenes" desaparecen de la edición de 2015. Las reescrituras apuntan a retrasar todo lo posible la llegada del "mal", de la enfermedad, y de esos detalles que rápidamente le darían un contexto concreto ("llagas", "ampollas" y "gérmenes"). Es una decisión creativa muy sutil, que busca desligar la novela de su contexto de enunciación, sin que eso la aleje tanto llevándola a un relato abstracto que no ofrezca ligazones con la realidad. Finalmente, el narrador enferma en ambas versiones, pero es una enfermedad que al no presentar "llagas" o "gérmenes" puede ser cualquier enfermedad, en cualquier momento y lugar. Se puede ir más lejos en la lectura de estas modificaciones y señalar que la "llegada del mal" dentro del relato, la enfermedad, va volviéndose indistinguible de aquella lectura que busca descubrir tras el nombre "enfermedad" una descripción literal del SIDA. La enfermedad literaria, o cierta "retórica del lector"10 que debilita el cuerpo de la obra, liga lo escrito a ese referente o contexto inicial: Bellatin reescribirá para desplazar todo lo posible esa lectura. ${ }^{11}$ Es un rechazo que no viene dado por una cuestión de gusto o de capricho subjetivo, sino porque el escritor ve que realmente la obra va cambiando frente a él. Porque paradójicamente, Salón de belleza adquiere más autonomía siempre en función del contexto que, nuevo cada vez, es cierto, viene a activar una siempre renovada pertinencia. Las reescrituras de la versión de 2015 muestran que el escritor trabaja a partir de las consecuencias de la "batalla ganada" por la novela ante el paso del tiempo y de la caída del primer contexto que la sujetó. Por un lado, esta "batalla ganada" es una especie de liberación de la obra, que puede funcionar en otros "entornos", pero simultáneamente es la espera de un encuentro con esos mismos entornos. Es lo que entendemos como plasticidad de la escritura bellatiniana: es un momento de la construcción narrativa que no se rige por una idea o plan inicial, sino que observa la confluencia temporal de factores que ofrecen a determinada escritura la posibilidad de cambiar, mutar de modo vertical; no es la horizontalidad de una historia que se sigue contando, que también se da en Bellatin, sino la espera programática por efectos no programados en la transmisión y difusión de esa escritura. ${ }^{12}$ Vale recordar el proceso de trabajo del escritor, al menos en la etapa en la que escribe y reescribe Salón de belleza. ${ }^{13}$ Es un proceso de escritura consistente en dos etapas. Primero, en palabras del autor, produce:

\begin{abstract}
una serie de material de escritura sin finalidad determinada, es decir, determinado libro o historia; y después viene el proceso de armar esa escritura para darle una forma que le permita ser transmitida, y así convertirse en un sistema de flujo. De esta manera consigo librarme de esa escritura y generar nueva volviendo al estado original. Recién con la publicación los textos se convierten en una suerte de archivo puesto que, si no estarían destinados a desaparecer, lo que me ha pasado con casi todo el material no publicado. Nunca me he tomado el trabajo de guardar nada. Entonces el verdadero archivo es el que se crea cuando la palabra se fija en una edición. Lo que no significa que los textos estén terminados (Bellatin, 2006c, p. 1).
\end{abstract}

El escritor maneja una concepción del archivo, por lo menos en esta cita, que coincide con la publicación, con el dar a conocer, con el estatuto social de lo editorial. Como está "destinado a desaparecer", el archivo funciona aquí como "instituyente y conservador" (Derrida y Vidarte, 1997, p. 15). Esto, el escritor lo afirma, no implica una formulación definitiva para los textos, ya que siguen evolucionando como bien lo vimos. ¿Pero entonces qué queda fijado en esa institucionalización de la primera edición? ¿Habrá que decir que se instala o simula una versión originaria que fija el errar de una escritura que, sin embargo, le sobrevive? Vale la pena destacar, en la misma entrevista, cuando Bellatin se refiere a una puesta en escena de Salón de belleza, que le permitió tener "una suerte de objetividad frente a los textos" (2006c, p. 4). Como ocurrió con Shiki Nagaoka, que primero fue una conferencia que el escritor convirtió en relato a la luz de las reacciones de lectores académicos, Bellatin parece privilegiar cierto "estado de archivación" de sus producciones, un cara a cara con su escritura objetivada. En la cita de más arriba, se puede notar que la objetivación es de corte operativo: se busca dar con una "serie de material de escritura" para luego realizar las subsiguientes operaciones (hacerla más transmisible, "escribir sin escribir”, etc). Esto no es algo que lo singularice por 
sí mismo; acaso sea una práctica o hábito común a muchos escritores. La especificidad bellatiniana está en la coincidencia entre objetivación y socialización, la entrada al "sistema de flujo" que hace que ambas dimensiones converjan. Esta etapa convierte el momento de la publicación en un punto de partida sin mayor jerarquía que las respuestas que despierta. Una obra, un fragmento de escritura, pasa a ocupar el lugar que antes ocupara la anécdota del peluquero que auxiliaba a VIH positivos. Es así que incluso las propias obras publicadas adquieran nombres de personajes cuando el escritor habla de sus condiciones de producción (ejemplo: Salón de belleza en Lecciones para una liebre muerta), gesto que no deja de ser problemático, ambiguo, y que marca las producciones más recientes del escritor. ${ }^{14}$ La escritura del fragmento se hace más visible en tanto fragmento: ya sea que esté visible tipográficamente como en Lecciones... o que se deduzca de lo digresivo de su escritura como en El libro uruguayo de los muertos (2012), su libro más extenso, pero que acusa lo fragmentario en la multiplicidad de narraciones; o como en El gran vidrio (2007) que jaquea el sentido con el planteo de "tres autobiografías", donde parece ficcionalizar este hecho de escribir diversas cosas al mismo tiempo. En todo caso, la pasión por el encuadre y el delineado - "No hay artista del fragmento que no sea un maniático del encuadre y el delineado" (Pauls, 2005, p. 10-11)- aumenta proporcionalmente con el distanciamiento de las novelas clásicas (la etapa de Salón de belleza). ${ }^{15}$ La apertura del "Sistema Bellatin", su definición "performer" (Laddaga, 2007), la economía de los festivales, congresos, así como la fluidez de los dispositivos digitales, predispone al autor a una escritura de corto aliento, de fragmentos que entran al "sistema de flujo" y se instituyen con mayor rapidez, siguiendo aquí el sentido de "archivo" que usa Bellatin en la entrevista citada. En este sentido, el retorno de Salón de belleza es el de su pérdida, en la medida en que desescribe lo ya escrito, lo ya instituido, lo ya "archivado". Podría formularse el fenómeno en estos términos: la preparación de la Novela viene después de la novela. En Bellatin, la novela está presente siempre y cuando la pensemos como una espectralidad que sobrevuela los fragmentos de escritura que, en un futuro anterior, habrán de actualizarla.

\section{3- LA LLEgada DE LOS PECES}

Resulta tentador trasladarse al momento en que efectivamente la novela se estaba preparando para ver si lo que vemos ahora ya tenía lugar en ese entonces. Repetir la operación de Bellatin con sus papeles viejos, ganar la batalla para esas primeras escrituras, pero sin la ventaja de contar con ese recorrido histórico que emancipará a la novela de su anécdota inicial. Tenemos, eso sí, un recorrido histórico "menor": el que hace la escritura a través de las distintas versiones. Porque Bellatin repite el gesto de socializar y convertir su escritura cuando entrega en salvaguarda sus manuscritos a un grupo de investigadores en crítica genética de La Plata, que los estudian y organizan en el marco de un Archivo Bellatin establecido en la CriGAE-IdIHCS (Área de Investigación en Crítica Genética y Archivos de Escritores) (UNLP-CONICET). ${ }^{16}$ Es decir, sus propios papeles de trabajo, sin pasar por instancias editoriales, constituyen un caso más de esa obra en movimiento, no un camino hacia la obra, hacia su preparación, sino la obra yendo hacia ellos, en la medida en que, a partir de una operación crítica explícita y puesta en circulación, se convierten en pre-textos de una creación literaria. ${ }^{17}$ Este pre-texto, con el que ahora trabajaremos, es uno de los primeros manuscritos de Salón de belleza, cuando los rasgos más identificables del autor todavía no se han hecho cuerpo. ${ }^{18}$ Es que el lenguaje bellatiniano no siempre ha sido "preciso, frío y casi clínico" (Palaversich, 2003, p. 34). Si bien puede notarse que Salón de belleza está dicha con un gran desapego emocional, ${ }^{19}$ esto no es totalmente cierto, o lo es sólo parcialmente si atendemos a la visibilidad de ese decir. Me refiero a los peces, que en la novela tienen una atención más perfilada, a diferencia de los personajes humanos, que no tienen nombre ni profundidad. ${ }^{20}$ Existen algunas lecturas críticas que hacen foco en esta presencia de lo animal en la obra del escritor mexicano (Fernandes Ciprestre, 2018; Oliveira, 2019), pero aquí nos interesa ir más allá de lo figurativo o imaginario y aportar intelección a la génesis de estos peces: creemos que están ahí flotando en ese lenguaje "frío y casi clínico" 
porque son producto del movimiento del lenguaje, de su construcción, y no un elemento planificado antes de la escritura.

$\mathrm{Al}$ menos en los papeles, había otra cosa en el lugar donde ahora están los peces. Uno de los primeros borradores de la novela revela que Salón de belleza estaba planteada en tercera persona: el protagonista, que en la versión actual corresponde a un narrador en primera persona, es en estos documentos el "dueño" del salón de belleza que está acompañado por otros dos "estilistas". Puede suponerse con seguridad que estamos en presencia de una de las primeras versiones del relato: el borrador está escrito en una máquina de escribir underwood, dispositivo que Bellatin usó en sus comienzos, y además se registran varios ensayos de un comienzo para la propia novela, varios íncipits recomenzados en cada papel e incluso tenemos el caso de un íncipit recomenzado en un mismo documento. Este comienzo de la novela será relegado, desplazado hacia el interior de la novela, y remplazado por el relato de los peces. Recupero la primera parte del folio 1 de ese borrador (Figura 1):

\section{FIGURA 1}

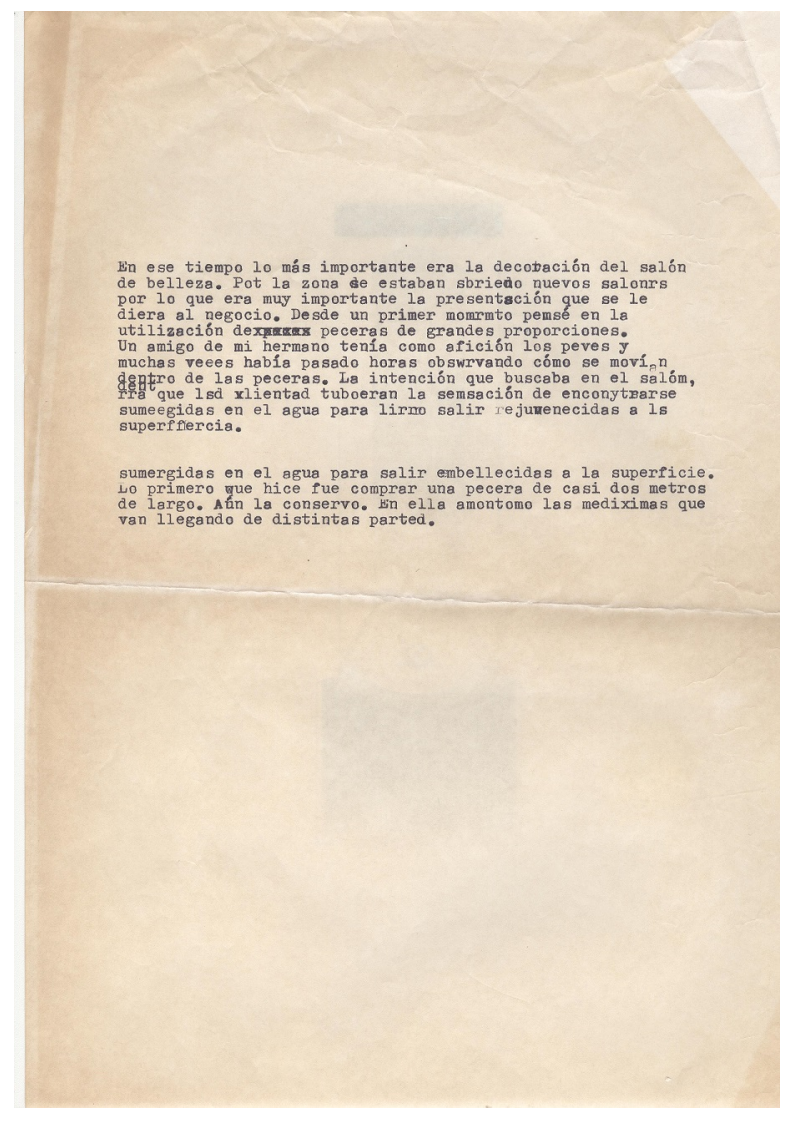

El salón de belle

Antes de ser un lugar usado exclusivamente para cobijarse para morir, el salón de belleza cerraba a las ocho de la noche. Era una buena hora para hacerlo, pues muchas de las clientas preferían no visitar tan tarde la zona donde estaba ubicado el establecimiento.

Antes de convertirse en un lugar usado exclusivamente para morir en paz compañía, el salón de belleza cerraba sus puertas a las ocho de la noche...

El sintagma inconcluso "El salón de belle" corresponde al íncipit "El salón de belleza cerraba sus puertas a las ocho de la noche...", abandonado aquí, en la misma hoja, por lo que sigue, un comienzo más fuerte en información ya que mediante la adición de la subordinada temporal "Antes de ser", plantea el asunto principal de la novela en esas pocas líneas. Es notable la insistencia y el trabajo en este íncipit: será retomado en cada folio de este borrador. Este estado de escritura lleva aguas a la idea de que este era un comienzo de la novela, y 
que un rápido vistazo a las últimas versiones deja ver que ese íncipit queda relegado por el relato del narrador en primera persona sobre su afición a los peces y acuarios. ${ }^{21}$ Este último es la otra clave: el protagonista, que en la versión actual corresponde a un narrador en primera persona, es en estos documentos el "dueño" del salón de belleza, que está acompañado por otros dos "estilistas". No hay mención de los peces. Nuestra hipótesis es que los peces emergen con ese narrador y que el relato del cuidado de esos animales está hecho para ser referido por una primera persona que refleje los afectos, la atención y el cuidado minucioso, elementos que en un relato en tercera persona se perderían, o que exigirían mayor descarga verbal en la descripción, opción que ya en esos momentos Bellatin estaba dejando fuera de la mesa. ${ }^{22} \mathrm{Si}$ los peces están mejor definidos que cualquier elemento de la novela, incluso que los personajes humanos, es por el vínculo especial que el narrador traba con ellos. Con el cambio de narrador, en consonancia con la lengua propia que Bellatin estaba construyendo, genera la condición de posibilidad del relato de los peces, que tan importante será para la lectura de la crítica, ${ }^{23}$ como para la que el propio autor hace cuando piensa la novela como "un espacio de reflexión entre la belleza y la muerte”. ${ }^{24}$ La lectura de un documento más, correspondiente al manuscrito número 5 de este conjunto de papeles, permite apreciar un paso intermedio de este proceso que venimos analizando. El documento en cuestión (Figura 2) está más próximo en el tiempo: físicamente el papel está menos amarillo por el paso de los años, incluso la tinta se presenta más oscura; y en base a nuestra hipótesis de lectura, ya presenta un narrador en primera persona con la introducción de la afición por los peces: "Desde un primer momento pensé en la utilización de peces peceras de grandes proporciones. Un amigo de mi hermano tenía como afición los peces y muchas veces había pasado horas observando cómo se movían dentro de las peceras". Este documento hace las veces de "eslabón perdido" entre Salón de belleza-tercera persona y Salón de belleza-primera persona: si bien ya está el narrador de primera, todavía está demasiado especificado, tiene un hermano y un amigo de éste que lo introduce al mundo de los acuarios. Estas referencias desaparecerán cuando llegue ese narrador indiferente, tendiente a lo neutral de las últimas ediciones, que estructuralmente nos acerca a lo referido pero en un movimiento que nos aleja: ya no hay hermano ni amigo del hermano, ya perdimos ese provechoso punto de vista que nos daba la tercera persona. Pero ahora tenemos los peces, que sólo pudieron salir a flote con un narrador fervoroso que, esta vez sí, no sustrae detalle alguno del comportamiento y cuidados requeridos por esos animales. Es la pequeña "batalla ganada" para el lector. El distanciamiento del lenguaje bellatiniano no nos deja un cuerpo textual en el aire, sin lazos con la realidad: desde unos pequeños peces hasta una pandemia global, algo termina por hacerse presente obligándonos a releer porque lo ya escrito sigue moviéndose. De ahí que el escritor rechace vincular Salón de belleza a un referente primitivo como si fuera su "escena verdadera": esta lectura es la llegada del mal, el quietismo moribundo de su letra, la muerte fijadora. 
FIGURA 2

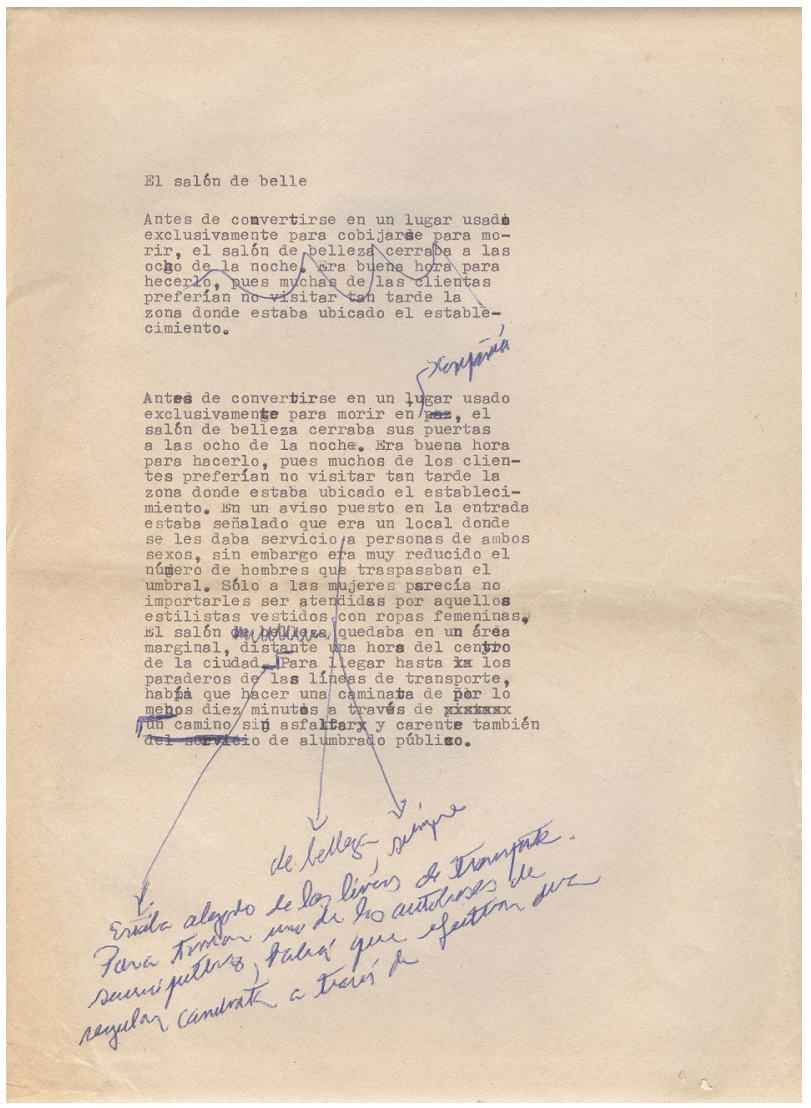

\section{CONCLUSIÓN}

Encontramos en Bellatin a un escritor receptivo y sensible a las lecturas que su escritura genera a lo largo de los años. Y también encontramos a un autor que escucha y corrige, un lector más si se quiere, con la ventaja de que puede batallar por la dirección de su escritura. En medio de todo esto, la novela o una versión de ella que se entrega como prenda (en el sentido jurídico de la palabra): acto que tiene como condición de posibilidad la separación progresiva de la escritura de su contexto de producción, de su emergencia aleatoria, accidental, para conseguir una literatura sin presupuestos externos, en tanto es "una praxis sin sanción" (Barthes, 2003, p. 205).

La estrategia de lectura crítica realizada aquí tuvo como condición de posibilidad ese mismo movimiento y ligó la lectura a una intervención: así, se va a sus papeles de trabajo y se los convierte en pre-textos a través de una operación de lectura que pretende liberarlos de un análisis que los limite a ser un material preparatorio para una obra a publicar. Movimiento, como decimos, que el propio autor hace con las instancias éditas de sus obras, a través de la recontextualización de las lecturas que éstas generan: prepara la novela antes de la novela (publicada).

\section{REFERENCIAS}

Antelo, R. (2001). Política de archivo. Revista Iberoamericana, LXVII (197), 709-720.

Barthes, R. (2003). Ensayos criticos. Buenos Aires: Seix Barral.

Barthes, R. (2005) La preparación de la novela: notas de cursos y seminarios en el Collège de France, 1978-1979 y 1979-1980. Buenos Aires: Siglo XXI. 
Bellatin, M. (1995). Tres novelas. Lima: Ediciones El Santo Oficio.

Bellatin, M. (1995). Deseo la ambigüedad: Mario Bellatin y Salón de belleza (entrevistador: Jorge Coaguila). La República, 25-6.

Bellatin, M. (1996) Salón de belleza y Efecto invernadero. México D. F.: Ediciones del Equilibrista/CONACULTA

Bellatin, M. (2005). Obra reunida. México: Alfaguara.

Bellatin, M. (2005). Lecciones para una liebre muerta. Barcelona: Anagrama.

Bellatin, M. (2006a). Hay como una búsqueda constante de escribir sin escribir, de resaltar los vacíos, las omisiones, antes que las presencias. Entrevista a Mario Bellatin (Ezio Neyra, entrevistador). Chile: Proyecto Patrimonio. Recuperado de http://www.letras.mysite.com/mb240606.htm.

Bellatin, M. (2006b) Pájaro transparente. Buenos Aires: Mansalva.

Bellatin, M. (2006c). Entrevista a Mario Bellatin (Ramiro Larrain, entrevistador). Orbis Tertius, 11(12)

Bellatin, M. (2009). Salón de belleza. México: Tusquets.

Bellatin, M. (2013). Obra reunida 2. México: Alfaguara.

Bellatin, M. (2014). Me siento escritor, cuando voy desescribiendo (Alicia Ortega, entrevistadora). Spondylus. Universidad Andina Simón Bolivar. Recuperado de https://www.uasb.edu.ec/web/spondylus/contenido?mari o-bellatin-34me-siento-escritor-cuando-voy-desescribiendo-34

Bellatin, M. (2015). Salón de belleza. La Plata: Malisia.

Cuartas, J.P. (2014). Los comienzos de Mario Bellatin: Tiempo y consistencia en Efecto invernadero (Tesis de grado UNLP) Recuperada de: http://www.memoria.fahce.unlp.edu.ar/tesis/te.1044/te.1044.pdf.

Derrida, J., Vidarte, P. (1997). Mal de archivo: una impresión freudiana. Madrid: Trotta.

Fernandes Ciprestre, K. (2018). Mario Bellatin: lo anómalo y lo animalesco transfigurados en erotismo. En Palma Castro, A [et al.] Bellatin en su proceso. Los gestos de una escritura. (pp. XX). Buenos Aires: Prometeo.

Goldchluk, G. (2000). Mario Bellatin, un escritor de ficción. Entrevista a Mario Bellatin, 7. Disponible en: https://filo logiaunlp.files.wordpress.com/2012/01/bellatin-un-escritor-de-ficcic3b3n.pdf

López Alfonso, F. J. (2015). Mario Bellatin, el cuadernillo de las cosas difíciles de explicar. San Vicente del Raspeig: Universidad de Alicante.

Laddaga, R. (2007). Espectáculos de realidad: ensayo sobre la narrativa latinoamericana de las últimas dos décadas. Rosario: Beatriz Viterbo Editora.

Martinetto, V. (2016). Mario Bellatin o la subversión de la autoficción: unas reflexiones a partir de Disecado. INTI, (83/84), 174-184.

Martínez Caballero, O (2011). La vertiente barroca de la literatura de Mario Bellatin. El Coloquio de los Perros. Revista de Literatura. "Mario Bellatin: el experimento infinito". (vol, año, p XX)

Nuyts, T. (2019). La dialéctica entre lo uno y lo múltiple. El sufismo de Ibn'Arabi en la narrativa de Mario Bellatin. Confluencia: Revista Hispánica de Cultura y Literatura, 34(2), 37-51.

Oliveira, E. J. D. (2019) Ficciones de la animalidad en América Latina: las formas animales en la literatura y en las artes visuales. Pasavento. Revista de Estudios Hispánicos, 7 (1), 79-96.

Palaversich, D. (2003). Apuntes para una lectura de Mario Bellatin. Chasqui, 32(1), 25-38.

Pauls, A. (2005). El problema Bellatin. El interpretador, 20, 10-11.

Rodríguez-Abruñeiras, P. (2014). Enfermedad, identidad y simbolismo en Salón de belleza, de Mario Bellatin. Letras, 85(122), 237-246.

\section{Notas}

1 Véase Flores, Gabriel (15 de febrero de 2020). “Los virus y las epidemias, contadas en cinco novelas de ficción”, en El Comercio. Disponible en: https://www.elcomercio.com/tendencias/virus-epidemias-novelas-ficcion-enfermedades. html. "Biblioteca de la peste" (17 mar. 2020), en Letras Libres. Disponible en https://www.letraslibres.com/mexico/lit 
eratura/biblioteca-la-peste. Baró, Carlos Olivares (20 mar. 2020). "Némesis, La peste, Decamerón y hasta La Biblia; los libros en tiempos de coronavirus", en La Razón. Disponible en https://www.razon.com.mx/cultura/nemesis-la-pestedecameron-y-hasta-la-biblia-los-libros-en-tiempos-de-coronavirus/. En virtud de que estos artículos no se utilizan en el presente trabajo, se los cita aquí y no en la bibliografía.

2 Lo relatado en esa obra parte de una anécdota que Bellatin retoma a grandes rasgos, sin entrar en detalle para no dejarse determinar por el hecho: "Partí de una noticia que encontré en un diario. Allí decía que había un peluquero que recogía enfermos de SIDA en un barrio marginal de Lima... A partir de este momento ingresó mi propia invención” (Coaguila, 1995, p. 25).

3 Se trata de elementos bíblicos en una disposición secularizada. "En cierto modo, Poeta Ciego constituye un punto de inflexión en la narrativa de Bellatin — con todas las reservas que exige una obra en continuo proceso-, pues supone una secularización de los viejos temas, o mejor, de sus presupuestos: el arte, la conciencia culpable, la familia social” (López Alfonso, 2015, p. 51).

4 Para esto, recuérdense las reacciones del escritor durante el contexto de producción de Poeta ciego, su sexta novela en orden de publicación. En una entrevista, Bellatin afirma: "Estaban también en el fondo todos esos escritores sociales, que se quedaron mudos de pronto, porque claro, no podían competir con los noticieros de televisión. Hubieran tenido que escribir novelas de veinticuatro horas para poder ganarle a la realidad. [...]Entonces ahí fue que yo me dije cómo puedo yo fijar esto, cómo congelar esto, cómo puedo hablar de esto, cómo lo puedo nombrar. O sea, por qué no lo puedo nombrar. Porque hay una retórica previa, porque yo no quiero entrar en ese juego ya determinado, porque no quiero entrar en una literatura que no me interesa (Bellatin en Goldchluk, 2000, p. 7).

5 "En Bellatin todo elemento autobiográfico no es verdadero ombligo, y si es ombligo ha sufrido tales y tantas mutaciones a lo largo de su obra, que se ha vaciado de realidad convirtiéndose en pura pieza de ajedrez en el tablero de un refinado juego literario" (Martinetto, 2016, p. 175).

6 "En Flores los hilos narrativos proliferan, las historias se entrecruzan de una manera más azarosa que premeditada; cada historia da nacimiento a otra como en un juego de cajas chinas" (Palaversich, 2003, p. 32).

7 La entrevista fue recuperada por el autor para formar parte del relato autobiográfico "Lo raro es ser un escritor raro", en Pájaro transparente(2006b).

8 Misma entrevista, sin paginación. En Pájaro transparente se omite la anécdota del moridero en Villa el Salvador, pero se señala el descubrimiento de nuevos y reales morideros: "cuando se realizó el montaje teatral en méxico d.f., el director de la puesta en escena, israel cortés, halló uno de esos refugios en las afueras de la urbe, y el grupo ensayó la obra en sus instalaciones" (2006b, p. 116, sin mayúsculas en el original).

9 También en el texto autobiográfico "Lo raro es ser un escritor raro", Bellatin señala que Salón de belleza cumple recién ahora con sus intenciones originales, al menos de modo más acertado, porque el avance en el tratamiento del sida desliga a la obra de ese referente en particular (Bellatín, 2006b, p. 116).

10 "Advertí entonces la presencia de una retórica del lector - muchas veces ignorada por pensarlo como suerte de tábula rasa-, que suele adelantarse a lo que está por leer. Quien lee parece que no tiene otra salida sino quedar siempre desilusionado, pues es casi imposible que una obra encuadre perfectamente con determinada fantasía” (Bellatin, 2006b, p. 108, el destacado es del original).

11 "Lo que más amenaza la lectura: la realidad del lector, su personalidad, su inmodestia, su manera encarnizada de querer seguir siendo él mismo frente a lo que lee, de querer ser un hombre que sabe en general” (Blanchot, 1992, p. 187).

12 Para un análisis más pormenorizado de esta idea me remito al capítulo 2 de mi tesis de grado (Cuartas 2014).

13 En la actualidad, el escritor se encuentra trabajando en sesiones de escritura en su underwood portátil: las sesiones consisten en la escritura de relatos que puedan desplegarse en el tamaño de una página y por medio de una sesión de escritura que no tenga un segundo momento de correcciones.

14 "Escribí Salón de belleza cuando escribía Salón de belleza, escribí Efecto invernadero cuando escribía Efecto invernadero, lo mismo con Canon perpetuo, pero no escribí Flores cuando escribí Flores y lo mismo sucedió con Lecciones. Lo que hice fue la segunda parte, la parte de construcción. Construí Lecciones cuando construí Lecciones y lo mismo con Flores. Con escrituras diversas, de diversos tiempos, situaciones y circunstancias. El reto era lograr que eso fuera una propuesta y formara parte de un cuerpo autónomo" (Bellatin en Larrain, 2006c, p. 7).

15 Entendemos por etapa clásica del proyecto escritural de Bellatin al conjunto de obras con las cuales consolidó determinados rasgos de escritura que persistirán más o menos hasta el presente. Es así que, si bien su primera novela publicada es Las mujeres de sal (1986), sostenemos que es a partir de 1992 con Efecto invernadero que el escritor descubre y construye una lengua personal, proceso que arbitrariamente finalizamos en Obra reunida de 2005, incluyendo novelas fundamentales como Salón de belleza (1994), Damas chinas (1995), Poeta ciego (1998), La escuela del dolor humano de Sechuán (2001), entre otras. Bellatin sigue trabajando su escritura hasta el presente, pero el cotejo de las obras y sus borradores nos da la pauta de que el "Sistema Bellatin" se apuntaló, en términos generales, en los años de aquella "etapa clásica”. Este argumento fue desarrollado en mi tesis de licenciatura (Cuartas, 2014). 
16 Este trabajo se inscribe en un espacio de reflexión articulado en el grupo de investigación "El archivo como espacio de intervención en América Latina. Políticas de exhumación, conservación y visibilización de archivos de la literatura y el arte". PICT de la Agencia de promoción científica, código BID-PICT 2018-02124.

17 Según relata Raúl Antelo en su trabajo con el archivo de Oliverio Girondo, las variantes escriturales del poeta no fueron consideradas "un hecho irreversible"; antes bien, se procedió bajo la hipótesis general de que "una obra no consiste en un texto; al contrario, es el texto (un gesto, una corporalidad) lo que persiste en cuanto obra (es decir, en cuanto operación colectiva y transtemporal) (Antelo, 2001, p. 713).

18 Existe una copia de este pre-texto en la página de la cátedra de Filología Hispánica de la UNLP, bajo el nombre de "Salón de belleza 1": https://filologiaunlp.files.wordpress.com/2015/03/salon-de-belleza-1.pdf. Al momento de escribir esto, ya está en proceso la puesta en línea de los manuscritos del autor en el sitio Arcas, de la Biblioteca de Humanidades de La Plata, portal de acceso abierto que incluye colecciones de fuentes que son reunidas en el marco de los proyectos de investigación acreditados de la Facultad de Humanidades y Ciencias de la Educación (FaHCE) de la Universidad Nacional de La Plata (UNLP) de Argentina. Con tres novelas ya organizadas Efecto invernadero, Canon perpetuo y, justamente, Salón de belleza, se proporcionará un valioso acceso abierto para futuras investigaciones.

19 "La emotividad no se asoma ni en las escenas que se refieren a la sexualidad ni en aquellas donde sería habitual esperar la compasión como en Salón de belleza donde el narrador-protagonista atiende las necesidades básicas de los moribundos" (Palaversich, 2003, p. 35).

20 "Se podría decir que los peces tienen una identidad mucho más perfilada y definida que cualquier otro elemento de la novela. Esto se evidencia especialmente si los comparamos con las personas: ninguno de los personajes tiene nombre propio, ni siquiera el narrador, y sin embargo sí tenemos una lista considerablemente extensa de razas de peces (Rodríguez-Abruñeiras, 2014, p. 238).

21 Otro indicio de que este era un comienzo original de la novela está en el hecho de que quedó un vestigio del viejo íncipit. Así comienza la edición de 2009: "Hace algunos años mi interés por los acuarios me llevó a decorar mi salón de belleza con peces de distintos colores. Ahora que el salón se ha transformado en un Moridero, donde van a terminar sus dias quienes no tienen dónde hacerlo, me cuesta trabajo ver cómo poco a poco los peces van desapareciendo" (Bellatin, 2009, p. 11, el destacado es nuestro). Vemos en cursiva, oculto, el comienzo de la underwood, que se repite en la página 23: "Antes de convertirse en un lugar usado exclusivamente para morir acompañado, el salón de belleza cerraba sus puertas a las ocho de la noche", pero que permanece aquí como un recordatorio sintomático. Las modificaciones se conservan en la reescritura de 2015.

22 Es decir, la correlación no es histórica, diacrónica, no tenemos datos para vincular narrador en primera persona con la subtrama de los peces, pero sí entendemos que ambos elementos son concurrentes para la eficacia sincrónica del relato constituyéndose, de este modo, en un “origen” (Agamben, 2001, p. 209-210).

23 Vale añadir un fragmento de Lecciones para una liebre muerta donde el propio autor hace mención de cómo el tema de los peces y la enfermedad ha sido leído y entendido. "Algunas personas creyeron descubrir la presencia de una enfermedad en particular mientras leían salón de belleza. Otras encontraron similitudes con los morideros que en la edad media servían como último lugar para todo género de apestados. Algunos más hallaron una serie de metáforas o puentes entre los peces y los personajes enfermos" (Bellatin, 2005, p. 131, el destacado es del original).

24 Ver nota 3. 